\title{
Humoral Immunity vs. Salmonella
}

\author{
Akiko Takaya ${ }^{1}$, Tomoko Yamamoto ${ }^{2}$ and Koji Tokoyoda ${ }^{3 *}$ \\ 1 Laboratory of Microbiology and Molecular Genetics, Graduate School of Pharmaceutical Sciences, Chiba University, Chiba, \\ Japan, ${ }^{2}$ Department of Infectious Diseases, Medical Mycology Research Center, Chiba University, Chiba, Japan, ${ }^{3}$ Deutsches \\ Rheuma-Forschungszentrum Berlin (DRFZ), A Leibniz Institute, Berlin, Germany
}

In primary infection with Salmonella, it has been reported-without consideration of Salmonella's functions - that humoral immunity plays no role in the clearance of bacteria. In fact, Salmonella targets and suppresses several aspects of humoral immunity, including B cell lymphopoiesis, B cell activation, and IgG production. In particular, the suppression of IgG-secreting plasma cell maintenance allows the persistence of Salmonella in tissues. Therefore, the critical role(s) of humoral immunity in the response to Salmonella infection, especially at the late phase, should be re-investigated. The suppression of IgG plasma cell memory strongly hinders vaccine development against non-typhoidal Salmonella (NTS) because Salmonella can also reduce humoral immune memory against other bacteria and viruses, obtained from previous vaccination or

OPEN ACCESS

Edited by:

Giuseppe Andrea Sautto, University of Georgia, United States

Reviewed by:

Carl De Trez,

Vrije University Brussel, Belgium

Mark L. Lang,

University of Oklahoma Health

Sciences Center, United States

${ }^{*}$ Correspondence:

Koji Tokoyoda tokoyoda@drfz.de

Specialty section:

This article was submitted to Vaccines and Molecular Therapeutics, a section of the journal

Frontiers in Immunology

Received: 25 October 2019

Accepted: 30 December 2019

Published: 21 January 2020

Citation:

Takaya A, Yamamoto $T$ and

Tokoyoda K (2020) Humoral Immunity

vs. Salmonella.

Front. Immunol. 10:3155.

doi: 10.3389/fimmu.2019.03155 infection. We propose a new vaccine against Salmonella that would not impair humoral immunity, and which could also be used as a treatment for antibody-dependent autoimmune diseases to deplete pathogenic long-lived plasma cells, by utilizing the Salmonella's own suppression mechanism of humoral immunity.

Keywords: humoral immunity, antibody, plasma cells, IgG, Salmonella

\section{INTRODUCTION}

The immune system, i.e., innate and adaptive immunity, can overcome many types of bacterial infections. The frontline against infection with bacteria such as Salmonella is innate immunity. Salmonella infection leads to enteric fever or diarrhea, often resulting in death of humans and animals. The pathogenesis of infection should be separately considered as two dynamics of the immune system vs. Salmonella: firstly, bacterial growth within 1 week after infection and, secondly, if protected from death, bacterial clearance after 1 week after infection. Early bacterial growth in mice is controlled by the Nramp gene, expressed in macrophages (1), and is suppressed by a T-cell-independent host response which requires granuloma formation and production of nitric oxide and cytokines such as tumor necrosis factor $\alpha$ (TNF $\alpha$ ), interleukin 12 (IL-12) and interferon $\gamma($ IFN $\gamma)(2-6)$. For clearance of the bacteria, innate immunity, namely the complement system and phagocytosis by macrophages, neutrophils and dendritic cells, are the most critical responses against the bacterial pathogens, while IFN $\gamma$ and antibodies resulting from adaptive immunity also dramatically enhance the innate immune response. It has been thought that adaptive immunity itself dominantly works for secondary infection except for IFN $\gamma$ from T cells. However, it remains enigmatic how adaptive immunity contributes to the clearance of Salmonella in the primary infection. We herein discuss the roles of humoral immunity against Salmonella for the clearance of the bacteria. 


\section{DEVELOPING A VACCINE AGAINST SALMONELLA}

Salmonella enterica is a Gram-negative intracellular bacterium with over 2,500 different serovars identified until now. Salmonella Typhi (S. Typhi) and S. Paratyphi cause typhoid fever, a systemic febrile illness only affecting humans. The other numerous NTS serovars such as $S$. Typhimurium and $S$. Enteritidis infect many different hosts and results in diarrheal disease. NTS also causes severe, extra-intestinal, invasive bacteremia, referred to as invasive NTS (iNTS) disease (7). Immunocompromised individuals, including those infected with human immunodeficiency virus (HIV) or malaria, and infants are particularly at risk of acquiring iNTS disease (8-12). iNTS disease is estimated to cause 3.4 million cases of illness and 681,316 deaths annually, with $63.7 \%$ of all cases occurring in children under the age of five (8). Thus, infection with NTS is still a serious health concern. Moreover, the emergence of multidrug-resistant strains of Salmonella calls into question the future use of antibiotics to treat infection and further emphasizes the need for the development of the safer and more effective vaccines. While a vaccine against NTS is not currently available, it has been reported that naturally acquired antibodies against NTS reduce the risk of iNTS disease $(13,14)$. In contrast, infection with $S$. Typhi can be prevented by vaccination with attenuated strains, e.g., Ty21a. However, effective vaccines preventing iNTS disease are likely to differ from those protecting against $S$. Typhi infections. Furthermore, it is known that Salmonella generates chronic carriers; a chronic carrier state has been identified in $2.2 \%$ of patients with reported NTS, lasting from 30 days to 8.3 years (15). Although Salmonella invades myeloid cells and escapes phagocytosis, it is unclear why humoral immunity does not contribute to the clearance of Salmonella which continuously transfers among short-lived myeloid cells. Overall, the lack of a vaccine and the presence of chronic carriers suggests that NTS suppresses long-lasting humoral immunity, i.e., humoral memory.

\section{THE IMMUNE SYSTEM VS. SALMONELLA}

Infection of susceptible $\mathrm{Nramp}^{-}$mice with $S$. Typhimurium provides a murine model for typhoid fever which bears many similarities to human $S$. Typhi infection. This $S$. Typhi model is ultimately fatal due to the inability of such mice to restrict bacterial growth in vivo. Administration of attenuated strains of $S$. Typhimurium as a model of vaccination resulted in the generation of immune memory against Salmonella and protection against death from challenge with a virulent strain of the bacteria $(16,17)$. The murine model infected with virulent $S$. Typhimurium showed similar pathogenesis on the early growth of bacteria. However, it seems unclear whether the model with attenuated $S$. Typhimurium really mimics the clearance of Salmonella, i.e., whether S. Typhi and S. Typhimurium are excluded from their hosts in a similar way. Many studies have discussed typhoidal disease using NTS strains based on the assumption that $S$. Typhi and $S$. Typhimurium utilize the same invasion system in the hosts. However, it is impossible to compare the mechanism on the clearance of Salmonella in vivo, because $S$. Typhi is not infectious in mice. If $S$. Typhi and $S$. Typhimurium are excluded by distinct bacterial clearances, the difference may affect the ability to generate vaccines against $S$. Typhi and S. Typhimurium.

Innate cells can have several roles to play during the early stage of an infection, including controlling bacterial replication and producing cytokines and chemokines that activate and recruit inflammatory cells to the site of infection. Macrophages, neutrophils and dendritic cells increase in number early after Salmonella infection and produce cytokines that are important for host survival, such as TNF $\alpha$. All three phagocytic cell types also harbor bacteria during infection. IFN $\gamma$ from natural killer cells at the very early infection phase and from $\mathrm{T}$ cells at the late infection phase can activate macrophages and promote phagocytosis (18). In addition to innate cells, the clearance of bacteria from the tissues also requires functional CD4 T cells (19), resulting in long-lasting specific immunity to re-challenge infection (20). Susceptible mice can resolve a primary infection with attenuated Salmonella strains which requires a functioning immune system that can develop a T-bet-dependent Th1 cell response and IFN $\gamma$ production to activate infected macrophages $(19,21)$. Similarly, mice lacking IL-12, IFN $\gamma$, reactive oxygen species, or inducible nitric oxide, all have deficiencies in primary clearance of Salmonella $(22,23)$. In contrast, mice lacking B cells resolve primary infection with attenuated bacterial strains with similar kinetics to wildtype mice $(24,25)$, indicating that $\mathrm{B}$-cell responses do not participate in the primary clearance of the bacteria. CD8 T cells are generally not thought to contribute to the primary clearance of attenuated Salmonella, based on studies using $\beta 2$-microglobulin-deficient mice that lack class I-restricted CD8 T cells $(19,26)$. However, recent experiments in mice lacking classical MHC class Ia genes, perforin, or granzyme, show that CD8 $\mathrm{T}$ cells make a modest contribution to Salmonella clearance during the later stages of the primary response (27). Overall, these data suggest a primary role for CD4 Th1 cells, a modest role for CD8 T cells and no role for $\mathrm{B}$ cells in primary immunity to Salmonella. However, the roles of adaptive immunity were considered from the viewpoint of how the lymphocytes respond to the infection, without any consideration of how Salmonella may purposefully subvert the immune response for its own advantage.

\section{HUMORAL IMMUNITY VS. SALMONELLA}

Immunization and infection with Salmonella greatly affects hematopoiesis in a TNF $\alpha$ - and CXCL12-dependent manner $(28,29)$. Salmonella is known to activate myelopoiesis and suppress B lymphopoiesis (30). Interestingly, the disruption of B lymphopoiesis has been also reported on Plasmodium infection in mice (31), suggesting the similar mechanism to Salmonella. This dramatic change in cellular commitment/differentiation is very reasonable, because in the early phase of infection, the immune system requires as many innate cells as possible to fight against the infection. Expanded myeloid cells are able to kill a 
lot of Salmonella, but some become the host cells for Salmonella without phagocytosis. Furthermore, the provision of B cells to the periphery is impaired due to death of B cell precursors in the bone marrow (BM), resulting in an indirect advantage to Salmonella for their long-term persistence.

In general, antibodies can protect against bacteria mainly by facilitating the uptake of the pathogen by phagocytic cells, which then destroy the ingested bacteria. Antibodies do this in two ways: one is to coat the pathogen to be recognized by Fc receptors on phagocytic cells, which is called opsonization. Alternatively, antibodies binding to the surface of a pathogen can activate the proteins of the complement system. Complement activation results in opsonization of the pathogen by binding complement receptors on phagocytes. Other complement components recruit phagocytic cells to the site of infection, and the terminal components of complement can lyse certain microorganisms directly by forming pores in their membranes. Most intracellular pathogens spread by moving from cell to cell through the extracellular fluids. The extracellular spaces are protected by humoral immunity. Antibodies produced by plasma cells cause the destruction of extracellular microorganisms and therefore prevent the spread of intracellular infections. Phagocytes, Salmonella's hosts, are short-lived and survive for 0.75 days (neutrophils, lifespan) (32), 18-20 h (phagocytic monocytes, half-life) (33), 1.5-2.9 days (dendritic cells, half-life) (34), and $<7$ days (peripheral macrophages, lifespan) (35). Therefore, in order to survive, Salmonella has to transfer into new host cells every 1-7 days passing through extracellular fluids containing antibodies. It is unknown how and why Salmonella can escape from antibodies in extracellular spaces when transferring into new host cells. In secondary immune responses, anti-Salmonella IgG are critical for the enhancement of phagocytosis. However, anti-Salmonella IgG in the late phase of the primary immune response does not contribute to the clearance of the bacteria (23). This raises the following questions: what is the difference of antiSalmonella antibodies in the primary and secondary immune responses? Is the affinity and/or amount of antibodies important? What other functions of Salmonella have to be also considered in the subversion of the immune response?

The activation of $\mathrm{B}$ cells and their differentiation into long-lived plasma cells is triggered by antigen and usually requires $\mathrm{CD} 4 \mathrm{~T}$ cell help, presenting antigen on $\mathrm{MHC}$ class II. Bayer-Santos and his colleagues showed that a Salmonella protein, SteD depletes surface MHC class II and inhibits T cell activation (36). SteD localized in the Golgi network and vesicles containing the E3 ubiquitin ligase MARCH8 and MHC class II causing MARCH8-dependent ubiquitination and depletion of surface MHC class II and B7-2. A subset of effector CD4 T cells, known as $\mathrm{T}$ follicular helper cells, also control isotype switching and have a role in initiating somatic hypermutation of antibody variable V-region genes for affinity maturation mainly in germinal centers (GCs) of the spleen. Cunningham et al. indicated that GC formation is delayed when infected with Salmonella (37). However, GC-lacking CD40L (CD154)deficient mice can normally induce the clearance of Salmonella in tissues. The formation of GCs and the affinity of antibodies do not affect the clearance of the bacteria. Di Niro et al. showed that Salmonella induces random activation, generating only a small fraction (0.5-2\%) of Salmonella-specific plasma cells, and somatic hypermutation occurred efficiently at extrafollicular sites (38). Although it should be investigated how the abnormal induction consequently affects the immune responses, it is very intriguing why Salmonella does not allow immune cells to utilize the standard immune activation/maturation pathways. Following GC formation, B cells can differentiate into either short-lived plasma cells, memory B cells, or long-lived plasma cells. Memory B cells persist and are important for secondary immune responses against the same pathogen. Short-lived plasma cells temporally provide IgG, but do not survive for long periods of time. In contrast, long-lived plasma cells, or their precursors, migrate into the BM and persist in CXCL12-expressing stromal cells $(39,40)$. In general, IgG is the most critical antibody isotype for the clearance of bacteria and greatly contributes to the clearance of bacteria at least in the late phase of infection. In contrast, in the clearance of Salmonella, no role of B cells which has a potential to differentiate into IgG-secreting plasma cells has been reported. The distinction led to a possibility of Salmonellaspecific suppression of humoral immunity, in particular IgG production as described below.

\section{SALMONELLA ATTACKS THE MAIN SOURCE OF IGG}

McSorley and Jenkins showed (i) that Salmonella can similarly survive in the tissues of naive wild-type and B cell-deficient mice until day 35 after infection, suggesting that antibodies and B cells are not necessary for the clearance of Salmonella, and (ii) that injection of heat-killed Salmonella induces a provision of anti-Salmonella IgG from day 20, although data of antiSalmonella IgG titers in mice infected with live Salmonella are lacking (24). However, if Salmonella actively suppresses $\mathrm{B}$ cell functions, the necessity of $\mathrm{B}$ cells for fighting the infection therefore fails to be evaluated by these studies. Very recently, we have shown that Salmonella inhibits the persistence of IgG-secreting plasma cells in the BM of mice, which are the main source of serum IgG, by secreting a Salmonella protein known as SiiE (41) (Figure 1). Mice infected with a SiiE-deficient strain markedly enhanced the provision of anti-Salmonella IgG and promoted the clearance of Salmonella, even in the primary infection. Given these results, the roles of antibodies and B/plasma cells therefore have to be re-evaluated.

SiiE is known as an adhesin, binding to carbohydrates in a lectin-like manner, thereby promoting attachment of Salmonella to polarized epithelial cells and enabling colonization $(42,43)$. SiiE is secreted by Salmonella and remains surface-associated during bacterial invasion (44). SiiE mediates the first direct contact to the host cell through binding to glycostructures containing $\mathrm{N}$-acetyl-glucosamine and/or $\alpha 2$, 3-linked sialic acid (45). Recently, Li et al. suggested that MUC1, the transmembrane mucin that is highly expressed at mucosal surfaces including the stomach and the intestinal tract, is a receptor for SiiE that enables apical invasion into enterocytes (46). 


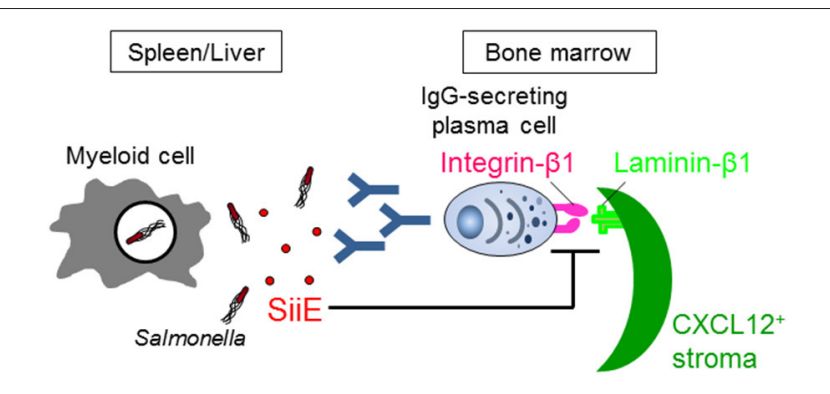

FIGURE 1 | Salmonella SiiE suppresses the retention of lgG-secreting plasma cells in BM survival niches by competing with laminin $\beta 1$. SiiE secreted by Salmonella competes with laminin $\beta 1$ to interact with integrin $\beta 1$. The competition induces the detachment and then deletion of lgG-secreting plasma cells from laminin $\beta 1^{+} \mathrm{CXCL} 12^{+}$survival niches of the BM.

SiiE is a large protein with a molecular weight of $595 \mathrm{kDa}$. It has 53 highly similar repeats of bacterial immunoglobulin (BIg) domains that determine the length and only short protein moieties of distinct structure at the very $\mathrm{N}$ - and C-terminal parts (43). The amino acid sequence from 129 to 168 in the short $\mathrm{N}$-terminal moiety has high homology to murine laminin $\beta 1$. The 236 amino acid residues in the short $\mathrm{N}$-terminal moiety consist of eight heptad repeats with a coiled-coil structure that are flanked by regions with a predominantly $\beta$-sheet structure (43). The integrity of the coiled-coil structure is required for the proper retention of SiiE and thereby affects invasion of polarized cells, while the $\beta$-sheet domains appear to be essential for the control of release of SiiE. The central part of the coiled-coil structure, including amino acids 129-168, plays an especially essential role in the retention of SiiE (43). The homologous region in the $\mathrm{C}$-terminal region of laminin $\beta 1$ also has a coiledcoil structure, which is involved in the assembly of a laminin molecule (47). The C-terminal region also modulates the integrin binding affinities of laminins (48). We showed that SiiE can bind to integrin $\beta 1$, a laminin receptor, on BM IgG-secreting plasma cells and competes with their adhesion to laminin (41). Only the SiiE-derived peptide which has high homology to murine laminin $\beta 1$ was able to reduce the number of BM IgG-secreting plasma cells. Moreover, the attenuated SiiE-deficient Salmonella enhanced both the production of high titers of protective IgG against Salmonella and the memory response, suggesting that it may be a novel and efficient vaccine against Salmonella. Histological analyses of the BM revealed that IgG- but not IgM-secreting plasma cells bind to laminin $\beta 1$. Thus, laminin $\beta 1^{+} \mathrm{CXCL} 12^{+}$stromal cells are an integral part of the survival niche for IgG-secreting plasma cells in the BM, a lesson learnt from Salmonella.

\section{ROLES OF HUMORAL IMMUNITY AGAINST SALMONELLA AND NEW GENERATION OF VACCINES}

Salmonella SiiE reduces the number of BM IgG-secreting plasma cells (41). This reduction may have led to the underestimation of the roles of $\mathrm{B}$ cells, especially antibodies, in the late phase of the primary infection with Salmonella. If IgG production is not suppressed by Salmonella SiiE, humoral immunity, in particular IgG, is required for the clearance of Salmonella in the late phase of the primary infection (41). Infection with SiiEdeficient strain into B cell-deficient and wildtype mice should be examined in order to determine the precise role of humoral immunity in the late phase of primary infection with Salmonella. Since vaccines against NTS are not yet available, SiiE-deficient Salmonella may be the first efficient vaccine against NTS. It still remains unclear why vaccines against $S$. Typhi, but not NTS are available. Intriguingly, the siiE gene in $S$. Typhi has been reported as two distinct ORFs, suggesting that it is a pseudogene (49). The presence of a functional SiiE gene may be a reason for the differences in availability of vaccines against the two strains of Salmonella. Furthermore, SiiE impairs the persistence of all IgG-secreting plasma cells in an antigen-specific independent manner. This non-specific depletion of IgG-secreting plasma cells may result in the loss of long-lived plasma cells secreting IgG against many kinds of bacteria and viruses generated by previous vaccination or infection. Therefore, generating vaccines against NTS may be essential to avoid such a loss of vital of humoral memory. Other pathogens may also have an ability to suppress humoral immunity. Recent studies indicated that respiratory syncytial virus (RSV) infection fails to induce in $\operatorname{IgA}^{+}$ memory B cells (50) and that measles causes elimination of $11-73 \%$ of the antibody repertoire and depletion of previously expanded B memory clones after infection (51, 52). However, cellular and molecular mechanisms on their suppression are still unknown and should be investigated, then comparing with the case of Salmonella.

\section{TREATMENT OF ANTIBODY-MEDIATED DISEASES USING A SALMONELLA-DERIVED PEPTIDE}

The SiiE peptide homologous to laminin $\beta 1$ significantly reduced the number of anti-DNA IgG-secreting plasma cells in the $\mathrm{BM}$ in the $\mathrm{NZB} / \mathrm{W}$ murine model of lupus nephritis (41). This property could therefore be further exploited for the treatment of autoimmune diseases. Autoimmune diseases with a substantial contribution of pathogenic IgG autoantibodies, like systemic lupus erythematosus, can be refractory to conventional treatment e.g., immunosuppressive drugs and anti-CD20 antibodies, because BM plasma cells secreting these autoantibodies are protected in their BM niches (53-55). Multiple myeloma is caused by redundant titers of antibodies generated from plasma cell myeloma in the BM. It has already been reported that myeloma cell lines preferentially contact laminin in vitro $(56,57)$, suggesting that targeting of adhesion molecules including laminin should be considered as novel therapy (58). The depletion of BM plasma cell myeloma by SiiE may directly ameliorate disease. SiiE peptide and the related products may contribute to a recovery for these antibody-mediated diseases without relapse. 


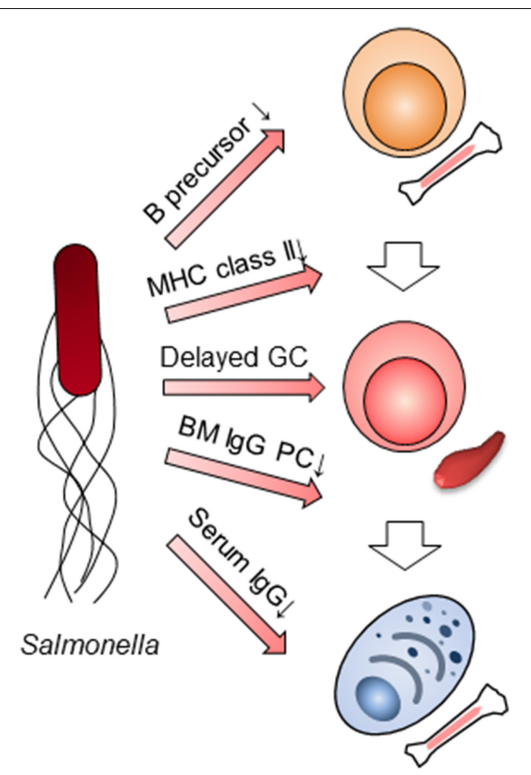

FIGURE 2 | Multilayer suppression of humoral immunity by Salmonella infection. Salmonella impairs humoral immunity at multiple stages; B cell lymphopoiesis, the expression of MHC class II in myeloid cells, germinal center (GC) formation, the persistence of BM lgG-secreting plasma cells (PC) and lgG titers in serum.

\section{CONCLUSIONS AND PERSPECTIVES}

Humoral immunity in the late phase of primary infection with Salmonella had been thought not to participate in the clearance of the bacteria. However, when taking into consideration Salmonella's functions, it is clear that several aspects of humoral

\section{REFERENCES}

1. Vidal SM, Malo D, Vogan K, Skamene E, Gros, P. Natural resistance to infection with intracellular parasites: isolation of a candidate for Bcg. Cell. (1993) 73:469-85. doi: 10.1016/0092-8674(93)90135-D

2. Umezawa K, Akaike T, Fujii S, Suga M, Setoguchi K, Ozawa A, et al. Induction of nitric oxide synthesis and xanthine oxidase and their roles in the antimicrobial mechanism against Salmonella typhimurium infection in mice. Infect Immun. (1997) 65:2932-40.

3. Kagaya K, Watanabe K, Fukazawa, Y. Capacity of recombinant gamma interferon to activate macrophages for Salmonella-killing activity. Infect Immun. (1989) 57:609-15.

4. Tite JP, Dougan G, Chatfield, SN. The involvement of tumor necrosis factor in immunity to Salmonella infection. J Immunol. (1991) 147:3161-4.

5. Kincy-Cain T, Clements JD, Bost KL. Endogenous and exogenous interleukin12 augment the protective immune response in mice orally challenged with Salmonella dublin. Infect Immun. (1996) 64:1437-40.

6. Muotiala A, Makela PH. The role of IFN- $\gamma$ in murine Salmonella typhimurium infection. Microb Pathog. (1990) 8:135-41. doi: 10.1016/0882-4010(90)90077-4

7. Feasey NA, Dougan G, Kingsley RA, Heyderman RS, Gordon MA. Invasive non-typhoidal salmonella disease: an emerging and neglected tropical disease in Africa. Lancet. (2012) 379:2489-99. doi: 10.1016/S0140-6736(11)61752-2 immunity, in particular the suppression of IgG production, does indeed contribute to the clearance of bacteria in the late phase of the primary infection (Figure 2). Using SiiE-deficient Salmonella, the collaboration between humoral immunity and other immune systems should be also re-evaluated. The function of other immune cells may be overestimated or underestimated due to the suppression of humoral immunity. Furthermore, the previous candidates of vaccines against NTS should be re-investigated by adding a mutation of SiiE. The combined mutations of Salmonella factors which interfere with immune systems may result in the development of the best vaccines against NTS. As infection with NTS may delete all IgG plasma cell memory gained by vaccination obtained from infancy, we therefore also alert to this danger and propose an obligatory use of vaccination against NTS in infancy.

\section{AUTHOR CONTRIBUTIONS}

AT and KT wrote the paper. TY supervised the work.

\section{FUNDING}

This work was supported by grants from the Leibniz Association (International Leibniz Research Cluster ImmunoMemory, KT), the German Research Council (DFG, TO944/2-1 and TO944/31, KT), the Institute for Global Prominent Research in Chiba University (AT), KAKENHI (18K07102, AT).

\section{ACKNOWLEDGMENTS}

We thank Mairi A. McGrath for your editing and scientific comments.

8. Ao TT, Feasey NA, Gordon MA, Keddy KH, Angulo FJ, Crump JA. Global burden of invasive nontyphoidal Salmonella disease, 2010. Emerg Infect Dis. (2015) 21:941-9. doi: 10.3201/eid2106.140999

9. Majowicz SE, Musto J, Scallan E, Angulo FJ, Kirk M, O'Brien SJ, et al. The global burden of nontyphoidal Salmonella gastroenteritis. Clin Infect Dis. (2010) 50:882-9. doi: 10.1086/650733

10. Crump JA, Heyderman RS. A perspective on invasive Salmonella disease in Africa. Clin Infect Dis. (2015) 61:S235-40. doi: 10.1093/cid/civ709

11. Uche IV, MacLennan CA, Saul A. A systematic review of the incidence, risk factors and case fatality rates of invasive nontyphoidal Salmonella (iNTS) disease in Africa (1966 to 2014). PLoS Negl Trop Dis. (2017) 11:e0005118. doi: 10.1371/journal.pntd.0005118

12. Park SE, Pak GD, Aaby P, Adu-Sarkodie Y, Ali M, Aseffa A, et al. The relationship between invasive nontyphoidal Salmonella disease, other bacterial bloodstream infections, and malaria in Sub-Saharan Africa. Clin Infect Dis. (2016) 62(Suppl. 1):S23-31. doi: 10.1093/cid/civ893

13. Gordon MA. Invasive nontyphoidal Salmonella disease: epidemiology, pathogenesis and diagnosis. Curr Opin Infect Dis. (2011) 24:484-9. doi: 10.1097/QCO.0b013e32834a9980

14. MacLennan CA, Gondwe EN, Msefula CL, Kingsley RA, Thomson NR, White $\mathrm{SA}$, et al. The neglected role of antibody in protection against bacteremia caused by nontyphoidal strains of Salmonella in African children. J Clin Invest. (2008) 118:1553-62. doi: 10.1172/JCI33998 
15. Marzel A, Desai PT, Goren A, Schorr YI, Nissan I, Porwollik S, et al. Persistent infections by nontyphoidal Salmonella in humans: epidemiology and genetics. Clin Infect Dis. (2016) 62:879-86. doi: 10.1093/cid/civ1221

16. Hoiseth SK, Stocker BA. Aromatic-dependent Salmonella typhimurium are non-virulent and effective as live vaccines. Nature. (1981) 291:238-9. doi: 10.1038/291238a0

17. Tennant SM, Levine MM. Live attenuated vaccines for invasive Salmonella infections. Vaccine. (2015) 33(Suppl. 3):C36-41. doi: 10.1016/j.vaccine.2015.04.029

18. Ingram JP, Brodsky IE, Balachandran, S. Interferon- $\gamma$ in Salmonella pathogenesis: new tricks for an old dog. Cytokine. (2017) 98:27-32. doi: 10.1016/j.cyto.2016.10.009

19. Hess J, Ladel C, Miko D, Kaufmann SH. Salmonella typhimurium aroA ${ }^{-}$ infection in gene-targeted immunodeficient mice: major role of $\mathrm{CD} 4^{+}$TCR$\alpha \beta$ cells and IFN- $\gamma$ in bacterial clearance independent of intracellular location. J Immunol. (1996) 156:3321-6.

20. Mastroeni P, Harrison JA, Hormaeche CE. Natural resistance and acquired immunity to Salmonella. Fundam Clin Immunol. (1994) 2:83-95.

21. Ravindran R, Foley J, Stoklasek T, Glimcher LH, McSorley SJ. Expression of T-bet by CD4 T cells is essential for resistance to Salmonella infection. J Immunol. (2005) 175:4603-10. doi: 10.4049/jimmunol.175.7.4603

22. Mastroeni P, Vazquez-Torres A, Fang FC, Xu Y, Khan S, Hormaeche CE, et al. Antimicrobial actions of the NADPH phagocyte oxidase and inducible nitric oxide synthase in experimental salmonellosis. II. Effects on microbial proliferation and host survival in vivo. J Exp Med. (2000) 192:237-48. doi: 10.1084/jem.192.2.237

23. Lehmann J, Bellmann S, Werner C, Schroder R, Schutze N, Alber G. IL12p40-dependent agonistic effects on the development of protective innate and adaptive immunity against Salmonella enteritidis. J Immunol. (2001) 167:5304-15. doi: 10.4049/jimmunol.167.9.5304

24. McSorley SJ, Jenkins MK. Antibody is required for protection against virulent but not attenuated Salmonella enterica serovar Typhimurium. Infect Immun. (2000) 68:3344-8. doi: 10.1128/IAI.68.6.3344-3348.2000

25. Mastroeni P, Simmons C, Fowler R, Hormaeche CE, Dougan, G. Igh-6 ${ }^{-/-}$(Bcell-deficient) mice fail to mount solid acquired resistance to oral challenge with virulent Salmonella enterica serovar Typhimurium and show impaired Th1 T-cell responses to Salmonella antigens. Infect Immun. (2000) 68:46-53. doi: 10.1128/IAI.68.1.46-53.2000

26. Lo WF, Ong H, Metcalf ES, Soloski MJ. T cell responses to Gram-negative intracellular bacterial pathogens: a role for $\mathrm{CD}^{+} \mathrm{T}$ cells in immunity to Salmonella infection and the involvement of MHC class Ib molecules. $J$ Immunol. (1999) 162:5398-406.

27. Lee SJ, Dunmire S, McSorley SJ. MHC class-I-restricted CD8 T cells play a protective role during primary Salmonella infection. Immunol Lett. (2012) 148:138-43. doi: 10.1016/j.imlet.2012.10.009

28. Ueda Y, Yang K, Foster SJ, Kondo M, Kelsoe G. Inflammation controls B lymphopoiesis by regulating chemokine CXCL12 expression. J Exp Med. (2004) 199:47-58. doi: 10.1084/jem.20031104

29. Ulich TR, del Castillo J, Ni RX, Bikhazi N. Hematologic interactions of endotoxin, tumor necrosis factor alpha (TNF alpha), interleukin 1, and adrenal hormones and the hematologic effects of TNF alpha in Corynebacterium parvum-primed rats. J Leukoc Biol. (1989) 45:546-57. doi: $10.1002 /$ jlb.45.6.546

30. Slocombe T, Brown S, Miles K, Gray M, Barr TA, Gray D. Plasma cell homeostasis: the effects of chronic antigen stimulation and inflammation. $J$ Immunol. (2013) 191:3128-38. doi: 10.4049/jimmunol.1301163

31. Bockstal V, Geurts N, Magez S. Acute disruption of bone marrow B lymphopoiesis and apoptosis of transitional and marginal zone B cells in the spleen following a blood-stage Plasmodium chabaudi infection in mice. J Parasitol Res. (2011) 2011:534697. doi: 10.1155/2011/5 34697

32. Pillay J, den Braber I, Vrisekoop N, Kwast LM, de Boer RJ, Borghans JA, et al. In vivo labeling with $2 \mathrm{H} 2 \mathrm{O}$ reveals a human neutrophil lifespan of 5.4 days. Blood. (2010) 116:625-7. doi: 10.1182/blood-2010-01-259028

33. Italiani P, Boraschi D. From monocytes to M1/M2 macrophages: phenotypical vs. functional differentiation. Front Immunol. (2014) 5:514. doi: $10.3389 /$ fimmu.2014.00514
34. Kamath AT, Henri S, Battye F, Tough DF, Shortman K. Developmental kinetics and lifespan of dendritic cells in mouse lymphoid organs. Blood. (2002) 100:1734-41. doi: 10.1182/blood.V100.5.1734.h81702001734_1734_1741

35. van Furth R. Origin and turnover of monocytes and macrophages. Curr Top Pathol. (1989) 79:125-50. doi: 10.1007/978-3-642-73855-5_6

36. Bayer-Santos E, Durkin CH, Rigano LA, Kupz A, Alix E, Cerny O, et al. The Salmonella effector SteD mediates MARCH8-dependent ubiquitination of MHC II molecules and inhibits T cell activation. Cell Host Microbe. (2016) 20:584-95. doi: 10.1016/j.chom.2016.10.007

37. Cunningham AF, Gaspal F, Serre K, Mohr E, Henderson IR, Scott-Tucker A, et al. Salmonella induces a switched antibody response without germinal centers that impedes the extracellular spread of infection. J Immunol. (2007) 178:6200-7. doi: 10.4049/jimmunol.178.10.6200

38. Di Niro R, Lee SJ, Vander Heiden JA, Elsner RA, Trivedi N, Bannock $\mathrm{JM}$, et al. Salmonella infection drives promiscuous B cell activation followed by extrafollicular affinity maturation. Immunity. (2015) 43:120-31. doi: 10.1016/j.immuni.2015.06.013

39. Moser K, Tokoyoda K, Radbruch A, MacLennan I, Manz RA. Stromal niches, plasma cell differentiation and survival. Curr Opin Immunol. (2006) 18:26570. doi: 10.1016/j.coi.2006.03.004

40. Tokoyoda K, Egawa T, Sugiyama T, Choi BI, Nagasawa, T. Cellular niches controlling B lymphocyte behavior within bone marrow during development. Immunity. (2004) 20:707-18. doi: 10.1016/j.immuni.2004.05.001

41. Manne C, Takaya A, Yamasaki Y, Mursell M, Hojyo S, Wu TY, et al. Salmonella SiiE prevents an efficient humoral immune memory by interfering with $\operatorname{IgG}^{+}$ plasma cell persistence in the bone marrow. Proc Natl Acad Sci USA. (2019) 116:7425-30. doi: 10.1073/pnas.1818242116

42. Gerlach RG, Claudio N, Rohde M, Jackel D, Wagner C, Hensel M. Cooperation of Salmonella pathogenicity islands 1 and 4 is required to breach epithelial barriers. Cell Microbiol. (2008) 10:2364-76. doi: 10.1111/j.1462-5822.2008.01218.x

43. Wagner C, Polke M, Gerlach RG, Linke D, Stierhof YD, Schwarz $\mathrm{H}$, et al. Functional dissection of SiiE, a giant non-fimbrial adhesin of Salmonella enterica. Cell Microbiol. (2011) 13:1286-301. doi: 10.1111/j.1462-5822.2011.01621.x

44. Morgan E, Bowen AJ, Carnell SC, Wallis TS, Stevens MP. SiiE is secreted by the Salmonella enterica Serovar Typhimurium Pathogenicity Island 4encoded secretion system and contributes to intestinal colonization in cattle. Infect Immun. (2007) 75:1524-33. doi: 10.1128/IAI.01438-06

45. Wagner C, Barlag B, Gerlach RG, Deiwick J, Hensel M. The Salmonella enterica giant adhesin SiiE binds to polarized epithelial cells in a lectin-like manner. Cell Microbiol. (2014) 16:962-75. doi: 10.1111/cmi.12253

46. Li X, Bleumink-Pluym NMC, Luijkx Y, Wubbolts RW, van Putten JPM, Strijbis K. MUC1 is a receptor for the Salmonella SiiE adhesin that enables apical invasion into enterocytes. PLoS Pathog. (2019) 15:e1007566. doi: 10.1371/journal.ppat.1007566

47. Hohenester E. Structural biology of laminins. Essays Biochem. (2019) 63:28595. doi: 10.1042/EBC20180075

48. Taniguchi Y, Ido H, Sanzen N, Hayashi M, Sato-Nishiuchi R, Futaki $\mathrm{S}$, et al. The $\mathrm{C}$-terminal region of laminin $\beta$ chains modulates the integrin binding affinities of laminins. J Biol Chem. (2009) 284:7820-31. doi: 10.1074/jbc.M809332200

49. Main-Hester KL, Colpitts KM, Thomas GA, Fang FC, Libby SJ. Coordinate regulation of Salmonella pathogenicity island 1 (SPI1) and SPI4 in Salmonella enterica serovar Typhimurium. Infect Immun. (2008) 76:1024-35. doi: 10.1128/IAI.01224-07

50. Habibi MS, Jozwik A, Makris S, Dunning J, Paras A, DeVincenzo JP, et al. Impaired antibody-mediated protection and defective IgA B-cell memory in experimental infection of adults with respiratory syncytial virus. Am J Respir Crit Care Med. (2015) 191:1040-9. doi: 10.1164/rccm.201412-2256OC

51. Mina MJ, Kula T, Leng Y, Li M, de Vries RD, Knip M, et al. Measles virus infection diminishes preexisting antibodies that offer protection from other pathogens. Science. (2019) 366:599-606. doi: 10.1126/science.aay6485

52. Petrova VN, Sawatsky B, Han AX, Laksono BM, Walz L, Parker E, et al. Incomplete genetic reconstitution of $\mathrm{B}$ cell pools contributes to prolonged immunosuppression after measles. Sci Immunol. (2019) 4:aay6125. doi: 10.1126/sciimmunol.aay6125 
53. Cheng Q, Mumtaz IM, Khodadadi L, Radbruch A, Hoyer BF, Hiepe F. Autoantibodies from long-lived 'memory' plasma cells of NZB/W mice drive immune complex nephritis. Ann Rheum Dis. (2013) 72:2011-7. doi: 10.1136/annrheumdis-2013-203455

54. Hoyer BF, Moser K, Hauser AE, Peddinghaus A, Voigt C, Eilat D, et al. Short-lived plasmablasts and long-lived plasma cells contribute to chronic humoral autoimmunity in NZB/W mice. J Exp Med. (2004) 199:1577-84. doi: 10.1084/jem.20040168

55. Hiepe F, Dorner T, Hauser AE, Hoyer BF, Mei H, Radbruch A. Long-lived autoreactive plasma cells drive persistent autoimmune inflammation. Nat Rev Rheumatol. (2011) 7:170-8. doi: 10.1038/nrrheum.2011.1

56. Kibler C, Schermutzki F, Waller HD, Timpl R, Muller CA, Klein G. Adhesive interactions of human multiple myeloma cell lines with different extracellular matrix molecules. Cell Adhes Commun. (1998) 5:307-23. doi: 10.3109/15419069809040300

57. Vande Broek I, Vanderkerken K, De Greef C, Asosingh K, Straetmans N, Van Camp B, et al. Laminin-1-induced migration of multiple myeloma cells involves the high-affinity $67 \mathrm{kD}$ laminin receptor. Br J Cancer. (2001) 85:138795. doi: 10.1054/bjoc.2001.2078

58. Neri P, Bahlis NJ. Targeting of adhesion molecules as a therapeutic strategy in multiple myeloma. Curr Cancer Drug Targets. (2012) 12:776-96. doi: $10.2174 / 156800912802429337$

Conflict of Interest: The authors declare that the research was conducted in the absence of any commercial or financial relationships that could be construed as a potential conflict of interest.

Copyright (c) 2020 Takaya, Yamamoto and Tokoyoda. This is an open-access article distributed under the terms of the Creative Commons Attribution License (CC BY). The use, distribution or reproduction in other forums is permitted, provided the original author(s) and the copyright owner(s) are credited and that the original publication in this journal is cited, in accordance with accepted academic practice. No use, distribution or reproduction is permitted which does not comply with these terms. 